\title{
COUPLING ANALYSES OF LIMITING EQUILIBRIUM STATE FOR NORMALLY CONSOLIDATED AND LIGHTLY OVERCONSOLIDATED SOILS
}

\author{
Akira Asaoka ${ }^{\mathrm{i})}$, Satoru Ohtsuka ${ }^{\mathrm{ii})}$ and Minoru Matsuo ${ }^{\mathrm{i})}$
}

\begin{abstract}
Limiting equilibrium state of saturated soils is solved taking into account drainage conditions during loading stage before reaching limit state. In analysis procedure, non-dilatant characteristics are assumed at limit state and then the failure problem discussed in the present study is concerned with normally consolidated and/or lightly overconsolidated soils.

When solving statically indeterminate limiting equilibrium state one needs constitutive relations at limit state. In saturated soils, however, since the constitutive relations are generally expressed in terms of effective stresses, an additional field equation is required in order to link a velocity field to a pore pressure field. Therefore the problem should be solved as a coupling problem between these two fields. Two distinct types are discussed, one is undrained problem and the other, fully drained problem. Topics covered in the present study are as follows:

(1) Undrained bearing capacity and excavation stability of soft clays,

(2) Bearing capacity under partly drained and/or partly swelling condition,

(3) Comparison between rapid loading condition and undrained condition, and

(4) Seepage failure of loose sandy soils under fully drained condition.
\end{abstract}

Key words: bearing capacity, clay, consolidation, drainage, effective stress, seepage (IGC: $\mathrm{E} 3 / \mathrm{E} 1)$

\section{INTRODUCTION}

When staturated soil is considered, the volume change of soil skeleton that should determine the degree of hardening of the soil is closely related to pore pressure behaviour. Stability analysis of saturated soils, therefore, can be considered in several ways according to a variety of drainage conditions during loadings. The discussion on "effective versus total stress analysis" made for the choice of strength parameters for design has been one of the most controversial topics for long time in the history of soil mechanics (e.g., Rochelle and Marsal, 1981).

As suggested in Tamura et al. (1984), the

i) Professor, Department of Civil Engineering, Nagoya University, Chikusa, Nagoya 464-01.

ii) Associate Professor, ditto.

Manuscript was received for review on May 26, 1989.

Written discussions on this paper should be submitted before April 1, 1991, to the Japanese Society of Soil Mechanics and Foundation Engineering, Sugayama Bldg. 4F, Kanda Awaji-cho 2-23, Chiyoda-ku, Tokyo 101, Japan. Upon request the closing date may be extended one month. 
stability analysis of soils should hopefully be discussed under statically indeterminate boundary conditions. This may be for the sake of generality, and the statically indeterminate limiting equilibrium problem can never be solved without the use of constitutive equations at limit state. In saturated soils, however, the constitutive relations are generally expressed in terms of effective stresses, while external forces are in the state of equilibrium with total stresses. The problem of saturated soils, therefore, should always be solved with the help of a soil-water coupling equation for determining unknown additional field variable, i.e., a mean effective stress or a pore water pressure. This is commonly accepted in the theory of consolidation and the same should also be introduced to the limiting equilibrium analysis of saturated soils.

The present study intends to discuss the coupling problems which possibly appear in the limit analysis of soils: the limiting equilibrium state is considered both in velocity field and in the field of pore pressure taking into account various types of drainage conditions before reaching limit state, i.e., from undrained through partly drained and/or partly swelling to fully drained conditions during loading. Throughout the paper, not only at critical state but also at any loading procedure soils are assumed to follow normally consolidated or lightly overconsolidated behaviour that was originally formulated in the "critical state soil mechanics (Schofield and Wroth, 1968)." The numerical solutions of these coupling problems will be illustrated in this study through simple yet fundamental engineering problems that should cover the following topics:

(1) Bearing capacity and excavation stability of soft clays under idealized undrained condition.

(2) Bearing capacity of soft clays under partly drained and/or partly swelling conditions which should occur due to finite loading rate with time. Following two types of surface loading are considered: one is the loading applied through "porous membrane", and the other, the loading directly made by a water pressure.

(3) Comparison of the bearing capacity of soft clays between in rapid loading condition and in perfectly undrained condition.

(4) Determination of a hydraulic boundary potential for the critical seepage force for the failure of loose sandy soils under the assumption of steady state water flow in soils, which is referred to in the present study as a coupling problem under fully drained condition.

All these problems are newly investigated in the present paper, but they are in a natural extension of the former two papers by the first and the second authors appeared in 1986 and 1987. For the detailed formulation and necessary referrences, see also these papers.

\section{LIMIT ANALYSIS AND EFFECTIVE STRESSES}

Limiting Equilibrium Equations in Terms of Total Stresses

Through minimizing internal plastic dissipation energy with respect to kinematically admissible velocity field, the upper bound theorem in plasticity reduces to the equilibrium equations of forces at limit state. In a case of continnum this can be shown clearly through finite element discretization technique on the basis of the assumption that there exists no discontinuity in the velocity field (Tamura et al., 1984). When global shape of spatial distribution of external forces is known (this is corresponding to a "flexible loading" and/or a "self/weight loading due to gravity"), and also when no rates of volume change is assumed at limit state, the limiting equilibrium equation with necessary constraint conditions are expressed as follows:

$$
\begin{aligned}
& \int_{V} B^{T} \boldsymbol{s} d v+L^{T} \lambda=\mu \boldsymbol{F} \\
& \boldsymbol{F}^{T} \dot{\boldsymbol{U}}=1 \\
& L \quad \dot{\boldsymbol{U}}=\mathbf{0} .
\end{aligned}
$$

The set of these equations was first introduced mathematically by Tamura et al. (1984), and the non discontinuity assumption in the velocity field may reflect the fact that a definite slip line is scarcely observed in a case of 
hardening material. It may be said that this was the fundamental finding for establishing the Critical State Soil Mechanics based on the triaxial testing results on axi-symmetric soil specimens (Schofield and Wroth, 1968). Eq. (1) represents the limiting equilibrium state of forces in a weak form, in which $s$ and $\lambda$ denote deviatoric stresses and mean total stresses in all elements, respectively and $\mu$, the critical load factor that should give the ultimate load $\mu \boldsymbol{F}$ where $\boldsymbol{F}$ expresses the prescribed spatial distribution of external forces with unit magnitude. $\dot{\boldsymbol{U}}$ in Eqs. (2) and (3) represents the vector of all nodal velocites, and the other symbols follow notations in the usual finite element formulation, i.e., $B$ is the matrix giving strain-displacement (strain ratevelocity) relations and $L$, the matrix defined such taht $\dot{\boldsymbol{v}}=L \dot{\boldsymbol{U}}$ where $\dot{\boldsymbol{v}}$, the rates of volume change of all elements.

Eq. (2) defines provisional norm of velocity vector. Since the flow rule itself defines only relative magnitudes among the elements of strain rate tensor, Eq. (1) with only the use of flow rule will give only direction of the velocity field at limit state.

Eq. (3) is a constraint condition on the admissible velocity field, which follows from the characteristics of the plastic potential function employed particularly in the analysis. Eq. (3) given here indicates simply that no rates of volume change should occur at all elements in the limit state, which reflects non dilatant characteristics of soils received at critical state. This is commonly observed in normally consolidated and lightly overconsolidated soils and the same may be expected in loose sandy soils.

\section{Constitutive Equations at Critical State in Terms of Effective Stresses}

Eqs. (1)-(3) are solved simultaneously with respect to velocity $\dot{U}$, mean total stress $\lambda$ and load factor $\mu$ with the use of constitutive equations which represent stress strain relationship at critical state. In the present study soils are assumed to follow the associated flow rule with the following type of yield function in terms of effective stresses:

$$
\varepsilon_{v}^{p}=f\left(\sigma_{i j}{ }^{\prime}, \sigma_{i j 0^{\prime}}\right)
$$

in which plastic volumetric strain $\varepsilon_{v}^{p}$ is a hardening parameter and both $\sigma_{i j}{ }^{\prime}$ and $\sigma_{i j o^{\prime}}$ represent current and initial effective stresses, respectively. The latter of which gives reference stress state from which plastic strain rate begins to be measured, i.e., $\varepsilon_{v}^{p}=0$ when $\sigma_{i j^{\prime}}=\sigma_{i j o^{\prime}}$.

Critical state is defined as the state at which the magnitude of strain rate becomes indeterminate even when no increments of stresses are applied. First, when no increments of stresses are considered, it follows from Eq. (4) that

$$
\dot{\varepsilon}_{v}^{p}=\dot{\varepsilon}_{v}^{e}=0 \quad \text { at critical state. (5) }
$$

Now, based on the normality assumption, the critical state condition in terms of effective stresses is obtained so that plastic multiplier may become indeterminate under no incremental stress condition, that is

$$
\frac{\partial f}{\partial \sigma_{i j}{ }^{\prime}} \delta_{i j}=0 \text {. }
$$

Note that no rates of volume change should happen at critical state although magnitudes of the other components of strain rate are still indeterminate (see Eq. (3)).

The limit state in the present study is defined as the state of equilibrium of forces at which all soil elements have reached the critical state and their associated plastic strain rates should satisfy compatibility conditions with non-zero velocity field (see also Eq. (2)).

The stress-strain rate relationship at critical state can be written concretely only when yield function is identified. The following two yield functions are examined in this study.

\section{Original Cam Clay Model}

Introducing the dilatancy coefficient $D$ (Shibata, 1963), the yield function of Cam clay (Schofield and Wroth, 1968) can be expressed as follows;

$$
\varepsilon_{v}^{p}=M D \ln \frac{p^{\prime}}{p_{0}^{\prime}}+D \eta
$$

in which $\eta$ denotes stress ratio $q^{\prime} / p^{\prime}$ where $q^{\prime}$ and $p^{\prime}$ are stress parameters :

$$
p^{\prime}=\sigma_{m}^{\prime}
$$




$$
q^{\prime}=\sqrt{\frac{3}{2} s_{i j} s_{i j}}
$$

When Eq. (7) is considered, the critical state condition, Eq. (6), reduces to a simple form :

$$
q^{\prime}=M p^{\prime}
$$

where $M$ is a critical state parameter. Concerning the stress-strain rate relationship at critical state, although the norm of strain rate becomes indeterminate, the nomality rule determines its direction uniquely in terms of stresses at critical state as follows:

$$
\dot{\varepsilon}_{i j}^{p}=\left(\sqrt{\frac{3}{2}} \frac{\dot{e}}{M} \frac{1}{p^{\prime}}\right) s_{i j}
$$

where $\dot{e}=\sqrt{\dot{\varepsilon}_{k l}^{p} l^{p} \dot{\varepsilon}_{k l}^{p}}$ is an equivalent plastic strain rate. Since stress parameters in Eq. (11) are those at critical state, then strictly, $p^{\prime}$ and $s_{i j}$ should be written as $\left(p^{\prime}\right)_{f}$ and $\left(s_{i j}\right)_{f}$, respectively. Eq. (11) shows that the plastic flow of Cam clay at critical state is absolutely identical to the plastic flow of rigid plastic Mises material. Details are found in Asaoka and Ohtsuka (1987).

The limit state of soils will be determined through solving Eqs. (1)-(3) with respect to $\dot{U}, \lambda$, (mean total stress) and $\mu$ by the substitution of Eq. (11) into Eq. (1). Although the inverse relationship of Eq. (11) necessary for this substitution is trivial, it should be noted here that one still needs an additional field equation since there still exsists an unknown indeterminate field variable $\left(p^{\prime}\right)_{f}$ in this relationship. This additional field equation is called in the present study a soil-water coupling equation. This is so, because the difference between the solutions of the mean total stress $\lambda$ and of the mean effective stress $\left(p^{\prime}\right)_{f}$ gives spatial distribution of pore pressure at limit state.

\section{Sekiguchi and Ohta's yield function}

In order to evaluate the effect of anisotropically consolidated initial stress state, Sekiguchi and Ohta (1977) introduced, instead of $\eta$, a new stress ratio parameter $\eta^{*}$ into their yield function :

$$
\eta^{*}=\sqrt{\frac{3}{2}\left(\eta_{i j}-\eta_{i j o}\right)\left(\eta_{i j}-\eta_{i j o}\right)}
$$

in which

$$
\eta_{i j}=\frac{s_{i j}}{p^{\prime}}, \quad \eta_{i j o}=\frac{s_{i j o}}{p_{0}^{\prime}}
$$

where $\eta_{i j o}$ denotes initial stress ratio for anisotropic consolidation. Their yield function takes the same form as that of the original Cam clay:

$$
\varepsilon_{v}^{p}=M D \ln \frac{p^{\prime}}{p_{0}^{\prime}}+D \eta^{*} .
$$

In this case the critical state condition, Eq. (6), is obtained as follows:

$$
M-\frac{3}{2 \eta^{*}} \eta_{i j}\left(\eta_{i j}-\eta_{i j o}\right)=0 .
$$

Concerning the stress-strain rate relationship at critical state, it follows from Eqs. (14) and (15) that

$$
\dot{\varepsilon}_{i j} p^{p}=\left(\sqrt{\frac{3}{2}} \frac{\dot{e}}{\eta^{*}}\right)\left(\eta_{i j}-\eta_{i j o}\right)
$$

in which $\eta_{i j}$ should be the stress ratio at critical state. Now, in order to get the inverse relationship, Eq. (16) is rewritten as follows:

$$
\eta_{i j}-\eta_{i j o}=\alpha \dot{\varepsilon}_{i j} p
$$

where $\alpha$ is a positive scalar. Using this $\alpha$, the new stress ratio parameter at critical state is found to be

$$
\eta *=\sqrt{\frac{3}{2}} \alpha \dot{e}
$$

Substituting Eqs. (17) and (18) into critical state equation, Eq. (15), one gets

$$
\alpha=\sqrt{\frac{2}{3}} \frac{M}{\dot{e}}-\frac{\dot{\varepsilon}_{i j}^{p} \eta_{i j o}}{\dot{e}^{2}}, \dot{e} \neq 0
$$

which completes the inverse relation concerned.

It should be stated that all these equations reduces to the corresponding Cam clay equations if the initial stress ratio $\eta_{i j o}=0$.

When solving limit state, a soil-water coupling equation is required also in the case of Sekiguchi-Ohta's clay for the determination of unknown field variable, i.e., mean effective stress distribution at limit state.

\section{UNDRAINED ANALYSIS}

Coupling Equations and Numerical Procedure In undrained analysis, it is assumed that 
there is no flow of water into or out of any soil element during whole procedure of loading (undrained loading). Since plastic volumetric strain is assumed to depend only on the final state of stress and independent of its loading path, and the same, in elastic strain, the undrained assumption

$$
\varepsilon_{v}^{e}+\varepsilon_{v}^{p}=0 \text { in } V
$$

yields a single field equation in terms of effective stresses, which should provide a coupling equation for undrained analysis.

\section{Cam clay model}

Here considered is the normally consolidated Cam clay. Referring to Fig. 1, suppose that undrained loading is made from the biginning of initial stress state. The initial stress state (point B in the figure) is assumed isotropic for the sake of theoretical consistensy in the original Cam clay modeling. In this simplest case, Eq. (20) reduces to

$$
M \frac{\lambda}{\lambda-\kappa} \ln \frac{p^{\prime}}{p_{0}^{\prime}}+\frac{q^{\prime}}{p^{\prime}}=0
$$

where $\lambda$ and $\kappa$ are compression and swelling indices, respectively. Substituting critical state condition (Eq. (10)) into this equation, the soil-water coupling equation concerned simply becomes

$$
\left(p^{\prime}\right)_{f}=p_{0}{ }^{\prime} \exp (-\Lambda)
$$

where

$$
\Lambda=1-\frac{\kappa}{\lambda} \text {. }
$$

As shown in Eq. (22), when undrained loading for Cam clay is considered, the mean effective stress state at limit state is determined only from the initial effective stress state, and is independent of boundary conditions for the undrained loading. However, excess pore pressure distribution is still dependent of the boundary conditions. This is because the mean total stress at limit state in the following equation

$$
(u)_{f}=(p)_{f}-\left(p^{\prime}\right)_{f}-\gamma_{w} z
$$

should be solved under prescribed boundary conditions. The third term in Eq. (24) denotes hydrostatic pressure at depth $z$.

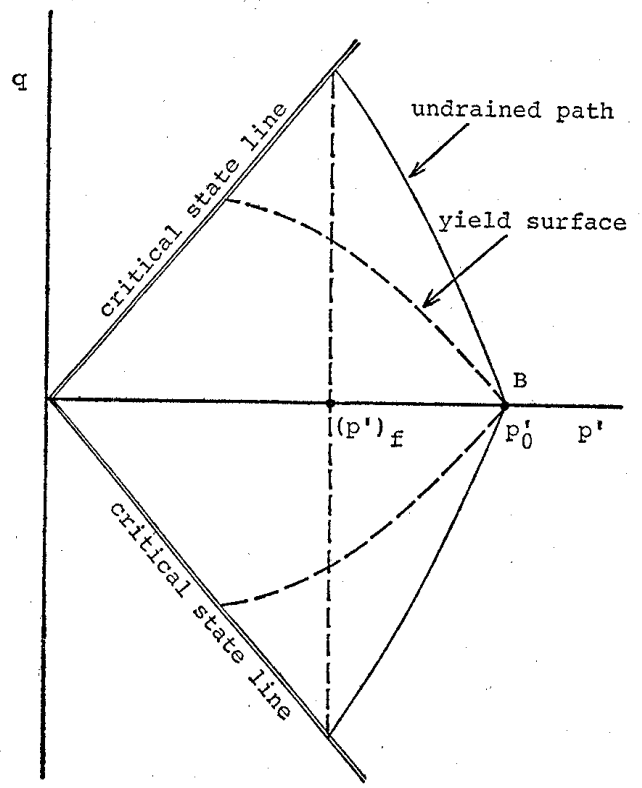

Fig. 1. Undrained path of original Cam clay model

\section{Sekiguchi-Ohta's model}

Normally consolidated soils ars considered first. Suppose that current effective stress state just before undrained loading is given on the

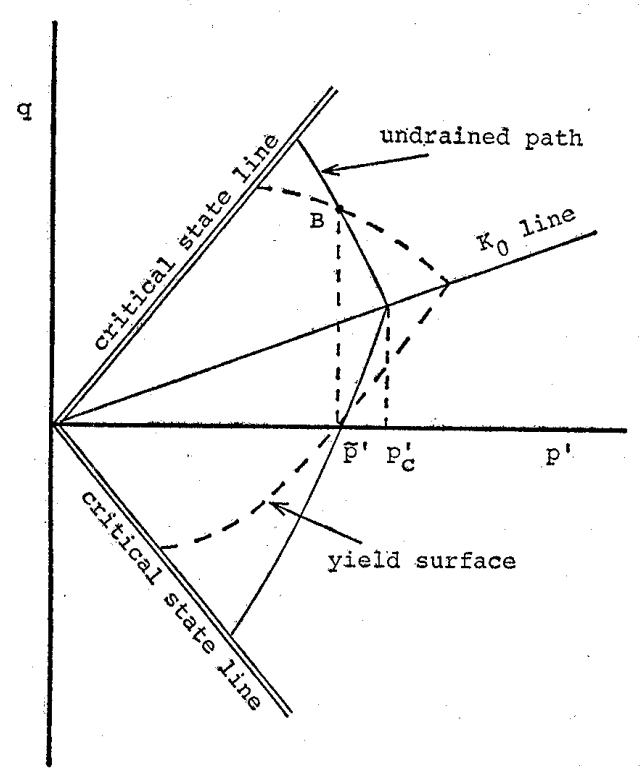

Fig. 2. Determination of $p_{c}^{\prime}$ for normally consolidated soil (Sekiguchi-Ohta's model) 
yield surface as plotted by point B in Fig. 2, in which Sekiguchi-Ohta's yield function is also illustrated. In this loading problem, since strains in Eq. (20) should be defined from point $B$, the undrained condition in terms of effective stresses is obtained as follows:

$$
\frac{M}{\Lambda} \ln \frac{p^{\prime}}{p_{c}{ }^{\prime}}+\eta^{*}=0
$$

where the parameter $p_{c}{ }^{\prime}$ can be determined by solving this equation through substituting current stress state, which yields

$$
p_{c}{ }^{\prime}=\tilde{p}^{\prime} \exp \left[\frac{A}{M} \sqrt{\frac{3}{2}\left(\frac{\tilde{s}_{i j}}{\tilde{p}^{\prime}}-\eta_{i j o}\right)\left(\frac{\tilde{s}_{i j}}{\tilde{p}^{\prime}}-\eta_{i j o}\right)}\right]
$$

where $\tilde{p}^{\prime}$ and $\tilde{s}_{i j}$ denote the stresses at point B. Now, since the stress ratio parameter $\eta^{*}$ at critical state has already been obtained in Eq. (18), the mean effective stress at critical state can be solved from Eq. (25) in terms of $p_{c}{ }^{\prime}$ as follows:

$$
\left(\hat{p}^{\prime}\right)_{f}=p_{c}^{\prime} \exp \left[\Lambda\left(-1+\sqrt{\frac{3}{2}} \frac{\dot{\varepsilon}_{i j}^{p} \eta_{i j o}}{M_{e}}\right)\right]
$$

which should be the coupling equation concerned. Since plastic flow at critical state $\left(\dot{\varepsilon}_{i j}{ }^{p}\right)_{f}$ appears in the second term in this equation, the limit state should be determined by solving Eqs. (1)-(3), Eq. (17) and Eq. (27), simultaneously. Those equations are solved iteratively with the use of Eq. (27), where the distribution of effective mean stress at critical state should be given in the first step. Unlike Cam clay computation, the mean effective stress at limit state is now dependent both of current stress state and of boundary conditions for undarined loading.

The discussion may become somewhat general when lightly overconsolidated soils are considered. Suppose that the current effective stress state is represented by point $A$ in Fig. 3. Referring to this figure, the parameter $p_{c}{ }^{\prime}$ in Eq. (27) is now obtained as a function both of current stress state and of its over consolidation ratio, that is

$$
p_{c}^{\prime}=\tilde{p}^{\prime} n^{\Lambda}
$$

where the overconsolidation ratio $n$ is defined as

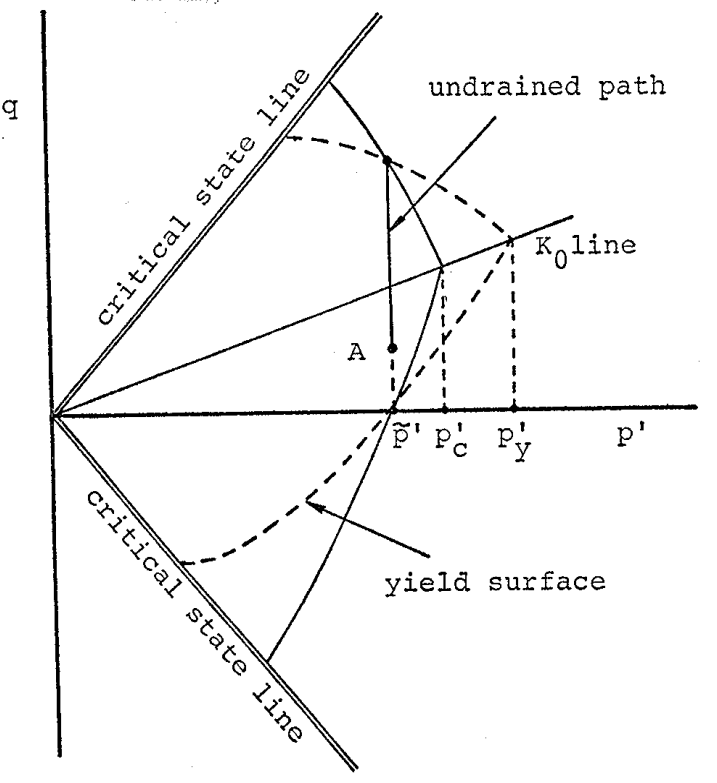

Fig. 3. Determination of $p_{c}{ }^{\prime}$ for overconsolidated soil (Sekiguchi-Ohta's model)

$$
n=\frac{p y^{\prime}}{\tilde{p}^{\prime}}
$$

in which $p y^{\prime}$ denotes yielding stress of the soil in $K_{0}$-consolidation procedure as shown in Fig. 3.

Note that all the equations obtained above are applicable for Cam clay computation when $K_{0}=1$ condition is considered for the initial stress state in the Sekiguchi-Ohta's model.

\section{IILUSTRATIVA EXAMPLES}

Bearing capacity of normally consolidated soft clays under flexible surface loading

The problem is considered here under plane strain condition. The necessary boundary conditions are defined in Fig. 4, in which initial vertical effective stress is also illustrated. The surface loading of $24 \mathrm{~m}$ in width is flexible, and the same, in overburden pressure. For simplicity, normally consolidated soft clay is simulated first by the Cam clay model, elastic plastic soil parameters of which are tabulated in Table 1. For the sake of theoretical consistency in Cam clay modeling, $K_{0}=1$ is assumed for the initial stress state as stated before. The results of limit state analysis are shown in Figs. 5 and 6 . Illustrated in Fig. 5 is the velocity field, while excess pore pressure distribution, in Fig. 6. As shown in these 


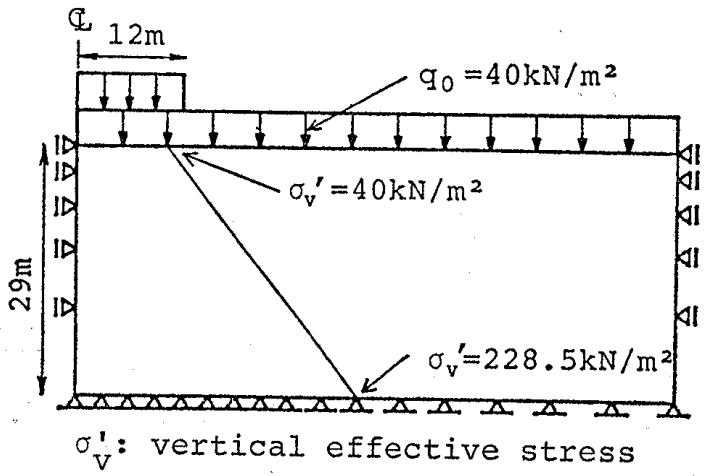

Fig. 4. Boundary condition and vertical stress distribution employed

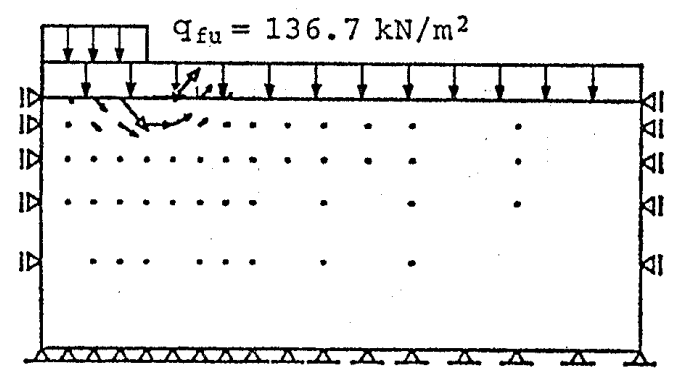

Fig. 5. Plastic flow at limit state in the case of original Cam clay

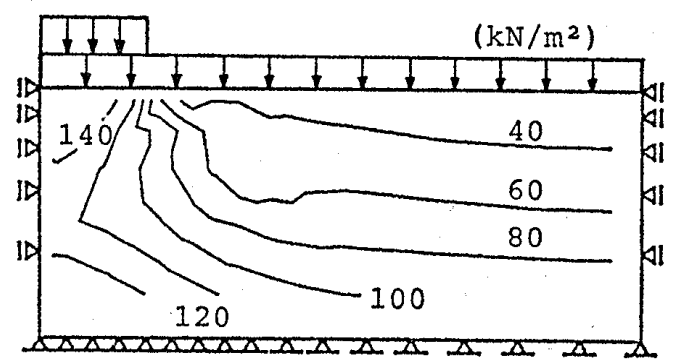

Fig. 6. Excess pore pressure distribution at limit state

figures the ultimate load intensity was calculated as $q_{f}=136.7 \mathrm{kN} / \mathrm{m}^{2}$. It is seen from the contour of equi-pore pressure line in Fig. 6 that the ultimate load applied on the top of clay is partly suspended by the seepage force.

The same problem was solved again assuming that the soil follows now the Sekiguchi-Ohta's model, where $K_{0}=0.7$ is considered for the initial stress state. Current effective stress state just before undrained loading is also assumed to be given by this initial stress state for simplicity. Initial vertical stress and elastic plastic soil parameters are the same as those
Table 1. Soil constants needed in the undrained analysis

\begin{tabular}{llll}
\hline$\lambda$ & 0.25 & $\kappa$ & 0.1304 \\
$M$ & 1.2 & $D$ & 0.033 \\
$\gamma \mathrm{t}$ & $16.3\left(\mathrm{kN} / \mathrm{m}^{3}\right)$ & & \\
\hline
\end{tabular}

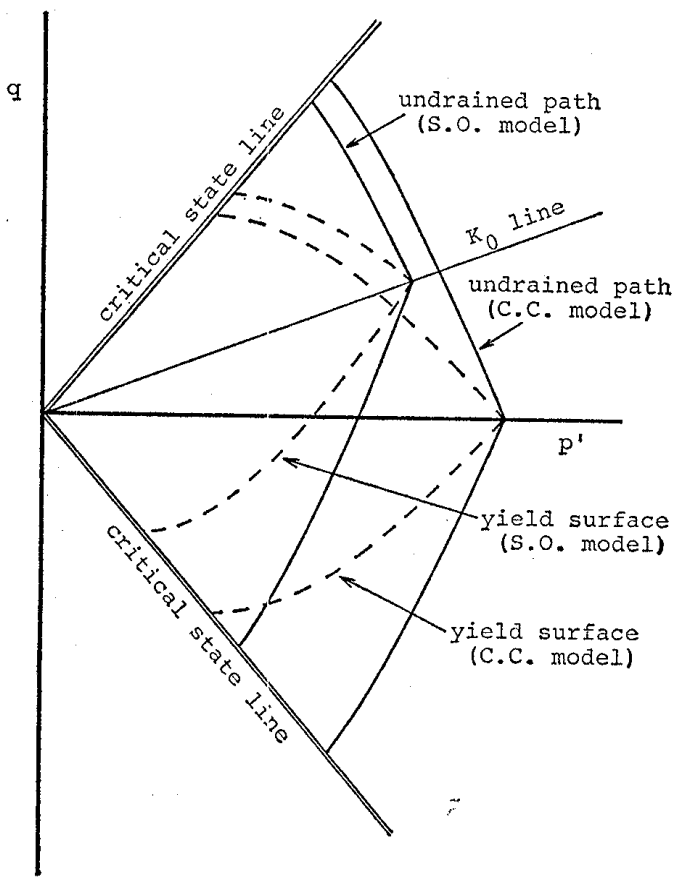

Fig. 7. Anisotropy of strength-deformation characteristics of Sekiguchi-Ohta's model

employed in the former Cam clay computation and are given in Fig. 4 and Table 1. Before giving the results of limit state analysis, the comparison of the yield functions between the Cam clay and the Sekiguchi-Ohta's clay is shown in Fig. 7. The yield functions are compared under axi-symmetric condition for the sake of easy illustration, in which the same vertical stress is assumed as mentioned above for the computation of initial stress state. From this figure, one can see that there is a significant difference in soil strength in extension side. When compared with Cam clay, the Sekiguchi-Ohta.'s model exhibits "initial stress induced anisotropic characteristics". both on strength and on the plastic flow, the discussion of which is, however, beyond the scope of the present study. See details in Ohta and 


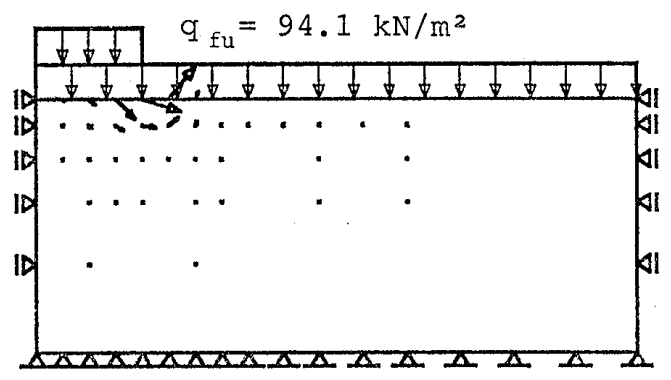

Fig. 8. Plastic flow in the case of SekiguchiOhta's model

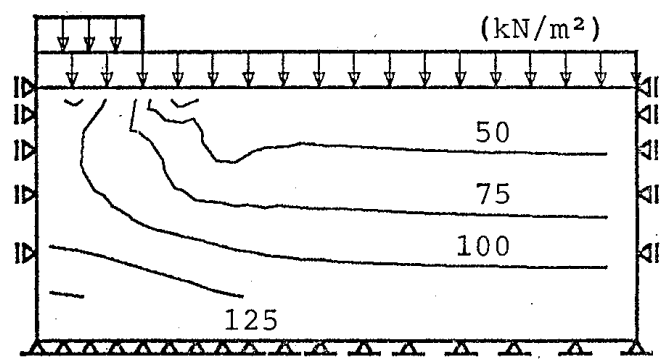

Fig. 9. Excess pore pressure distribution at limit state

Sekiguchi (1979), Sekiguchi and Ohta (1977), Ohta et al. (1985), Asaoka and Ohtsuka (1986, 1987).

The results of the limit state analysis for normally but anisotropically consolidated soils are illustrated in Figs. 8 and 9, which naturally give a smaller ultimate load than that of Cam clay.

Excavation of lightly overconsolidated soils under undrained condition

The lightly overconsolidated condition was made using the soils of Fig. 4 by removing the overburden pressure (Fig. 10). The current stress state especially for horizontal effective pressure before excavation was obtained through one dimensional computation of swelling. During whole procedure, soil is assumed to follow Cam clay model for simplicity. Excavation was made first axi-symmetrically down to $5 \mathrm{~m}$ in depth with a radius of $10 \mathrm{~m}$. Loading was applied under undrained condition by increasing gravity force artificially. Results of analysis are given in Figs. 11 and 12. Excavation stability is expressed in these figures by the safety factor in terms of the

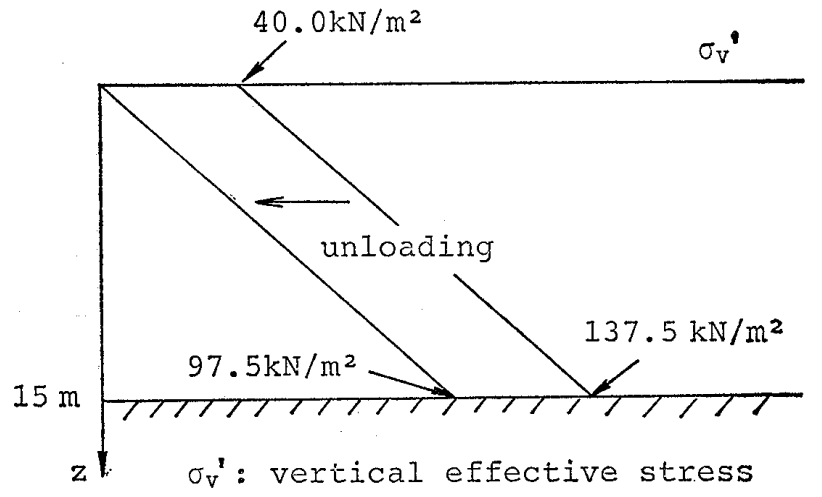

Fig. 10. Initial stress state employed for overconsolidated clys

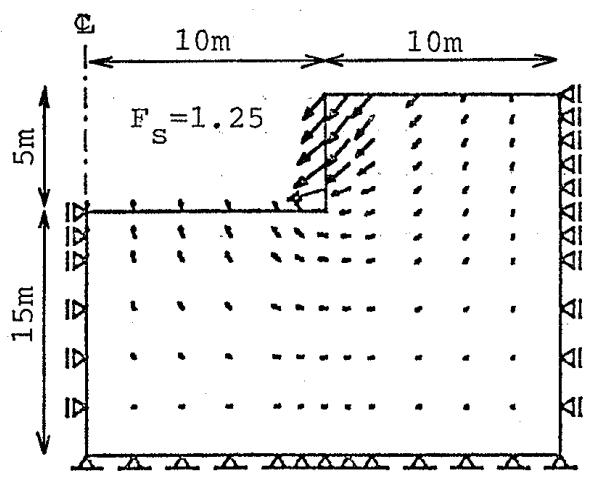

Fig. 11. Plastic flow of excavated ground under axi-symmetric condition

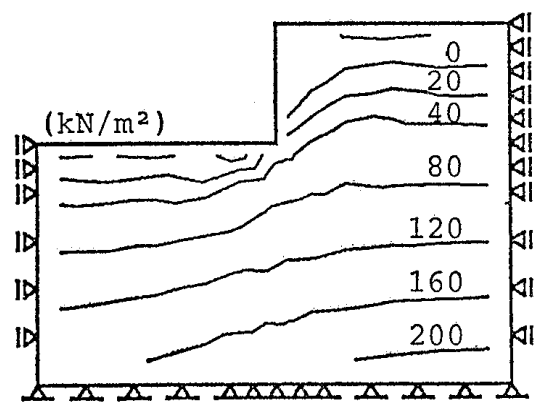

Fig. 12. Excess pore pressure distribution at limit state

ratio of the artificial gravity required for limiting equilibrium condition to the normal gravity.

Excavation stability depends highly on boundary conditions for the shape of excavated hole. Figs. 13 and 14 are corresponding to Figs. 11 and 12, respectively, but they are in plane strain conditions. As expected, the plane strain stability is lower than that in axi-symmetric conditions. Significant heaving 


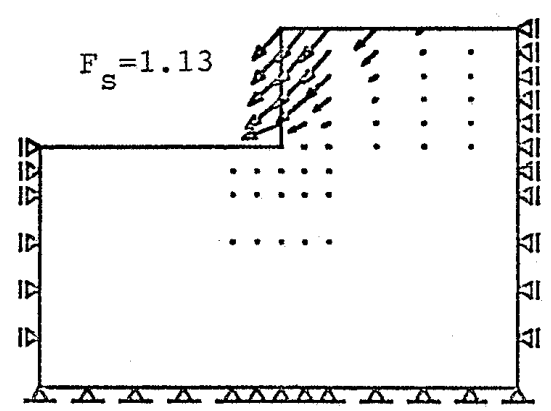

Fig. 13. Plastic flow of excavated ground under plane strain condition

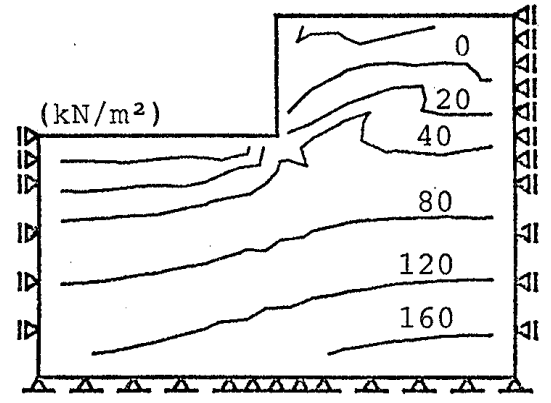

Fig. 14. Excess pore pressure distribution at limit state

at the bottom of excavation can be found in axi-symmetric case rather than in plane strain conditions.

\section{PARTLY DRAINED AND PARTLY SWELLING CONDITION}

Application of Undrained Analysis

From the view point of engineering practice, undrained loading may be a too idealized extreme condition. It is intended in this section, however, to show that undrained analysis gives a useful tool for the estimation of ultimate load that should be reached through partly drained and/or partly swelling loading conditions. Drained or swelling condition should occur due to finite rate of loading with time.

When undrained case is considered, the mean effective stress at critical state is determined proportionally with current effective stress state just before undrained loading, as investigated in Eqs. (22), (27) and (28). Therefore, ultimate load under undrained condition should change from time to time as current effective stress state changes. The

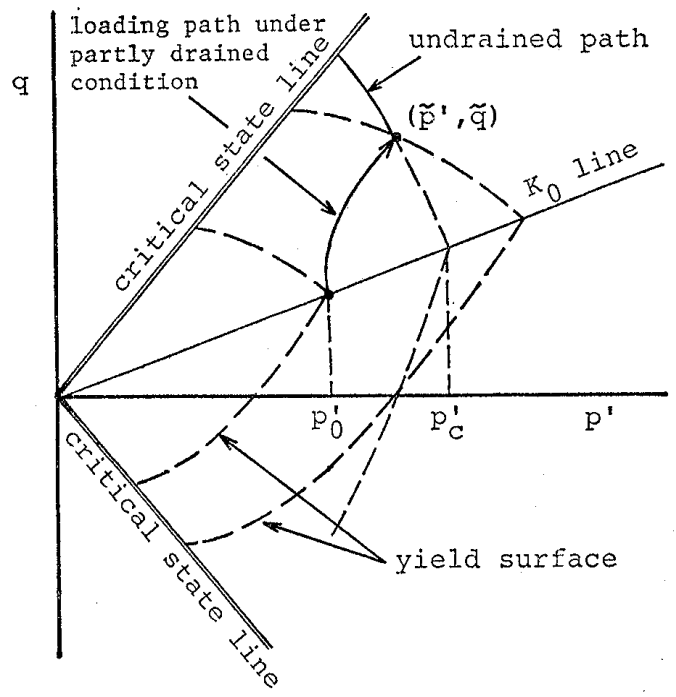

Fig. 15. The hardening procedure of soils
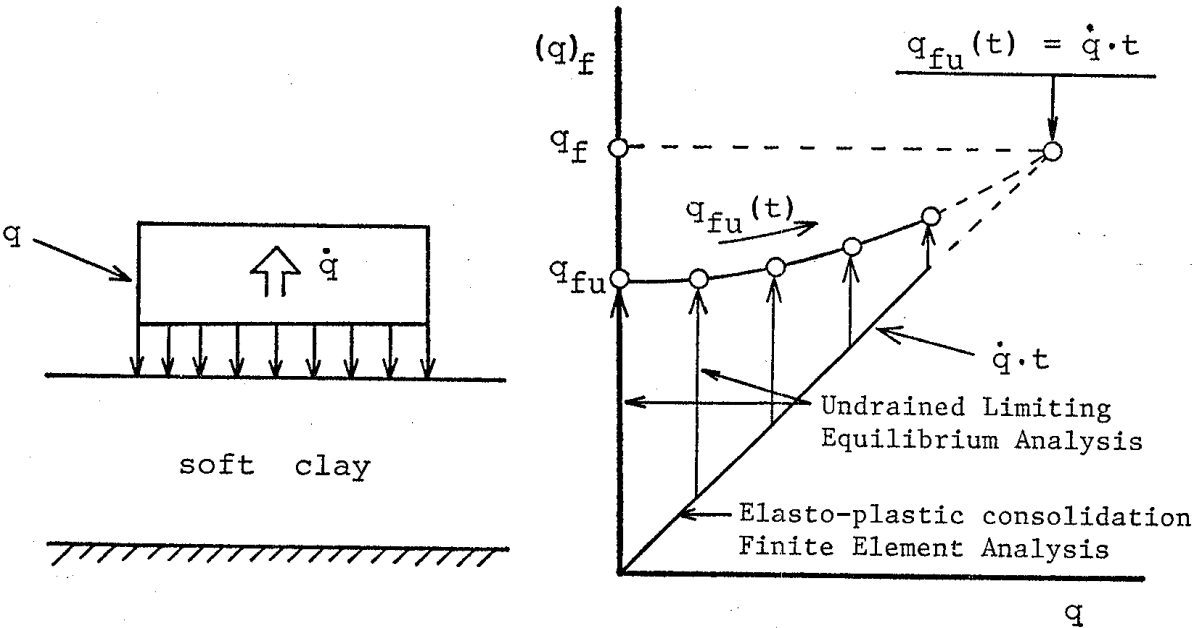

Fig. 16. The graphical method for estimating bearing capacity under partly drained condition 
current effective stress state should vary with time due to consolidation and/or swelling that should possibly happen with usual loading procedure. The move of current stress state is schematically illustrated in Fig. 15. As shown in this figure, strain hardening is much more expected to happen due to consolidation procedure than that, during undrained loading.

The ultimate load reached through partly drained and/or partly swelling condition is then estimated by extrapolation of a series of undrained limit analyses when the undrained bearing capacity is offered as a function of loading history. Embanking on soft clay with finite loading rate may be a typical bearing capacity problem that should be solved under partly drained condition. Fig. 16 shows a graphical scheme for the estimation of ultimate banking load achieved through gradual load application with time (Asaoka and Ohsuka, 1987). Elastic plastic multi-dimensional consolidation computation is to provide the move of current effective stress state from time to time.

\section{ILLUSTRATIVE EXAMPLES DISCUSSION}

\section{Loading through "porous membrane"}

The partly drained problem defined in Fig. 16 is solved here using the same boundary conditions and the same soil modeling (the original Cam clay) as given in Figs. 4-6 and Table 1. In these figures both top and bottom of the clay foundation are assumed fully permeable for the computation of elastic plastic consolidation procedure. Embankment loading in this example problem, therefore, is noticed being applied through "porous membrane (Fig. 17)". Coefficient of permeability employed

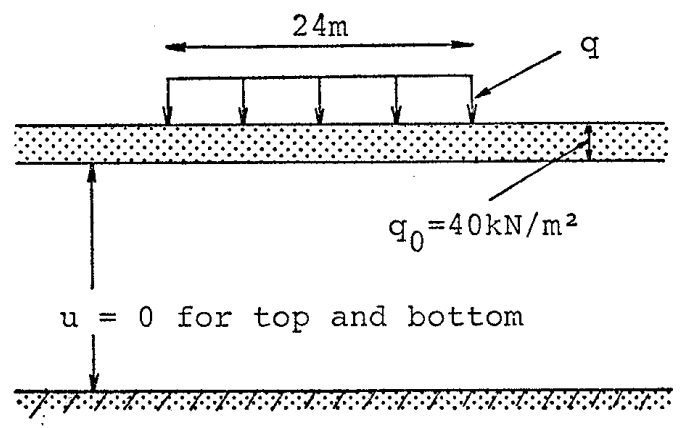

Fig. 17. Load application and drainage condition in the consolidation analysis is $k=5.88 \times 10^{-4}$ $\mathrm{m} /$ day.

A series of undrained limit analyses were carried out as current effective stress state moves with time. Fig. 18 summarizes the results. Partly drained bearing capacity is estimated by extrapolating $q_{f u}(t)$ towards $q=\dot{q} \cdot t$, which yields

$$
q_{f u}(t)=\dot{q} \cdot t=q_{f}
$$

as illustrated by dotted lines in Fig. 18. Next, the partly drained bearing capacity is examined for a variety of loading rates as summarized again in Fig. 19, which shows the bearing capacity being highly dependent of the loading rate.

In Fig. 19, another extrapolation is made to find out ultimate load intensity when rapid load application, i.e., $1 / \dot{q} \rightarrow 0$ is considered. The result should be compared with that given

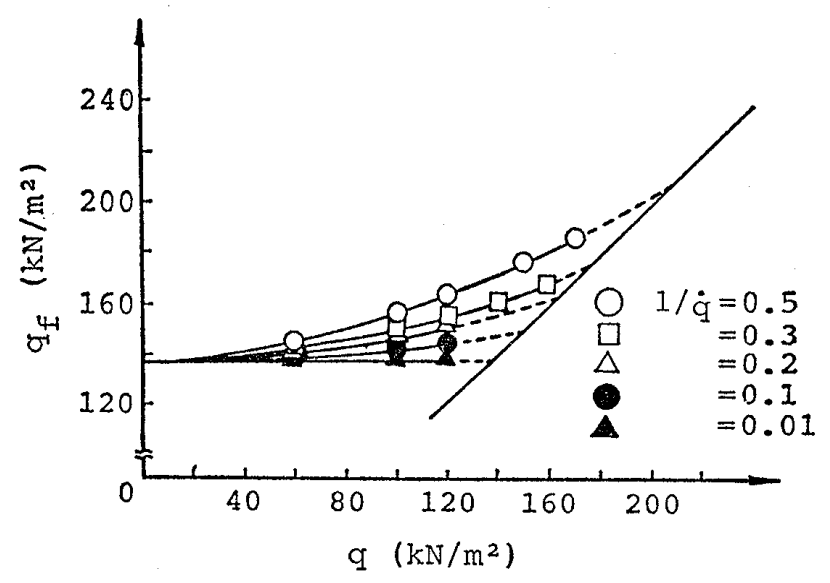

Fig. 18. Computation of partial drain effect

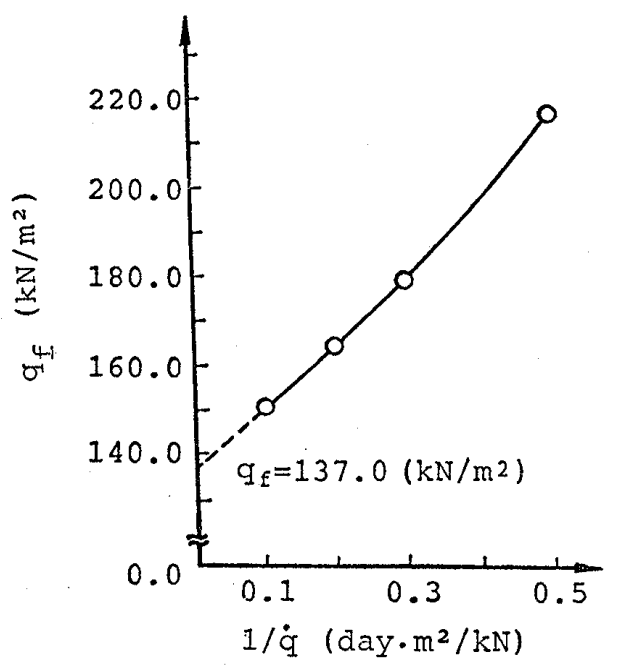

Fig. 19. Extrapolation of ultimate load intensity of rapid load application 
in Fig. 5. As commonly expected, the bearing capacity under rapid loading is well evaluated by the undrained analysis that was made taking the initial effective stress state before any load application into consideration.

The increase of bearing capacity due to gradual load application has ever been investigated widely by the direct use of elastic plastic consolidation deformation analysis (e.g., Shibata and Sekiguchi, 1980, 1981; Sekiguchi et al., 1981; Carter, 1982) and is called partial drain effect.

\section{Loading by a hydraulic potential boundary}

Here considered is a loading directly applied by water pressure without the use of any "membrane". In this problem, possible consolidation should occur due to seepage force, which may also induce swelling in both sides of loaded area. The loading conditions with necessary pore pressure boundary on the top of clay is illustrated in Fi.g 20, in which denotes the water head acting as a surface load. The other boundary conditions and soil modeling are exactly the same as those given in the former example problem. Based on these boundary conditions, elastic plastic consolidation and/or swelling deformation anlysis is first made in order to give current effctive stress state from time to time. The current effective stress state in a whole region of a soil mass should be the basic information for a series of undrained limiting equilibrium analyses as investigated above.

The series of analyses with a wide variety

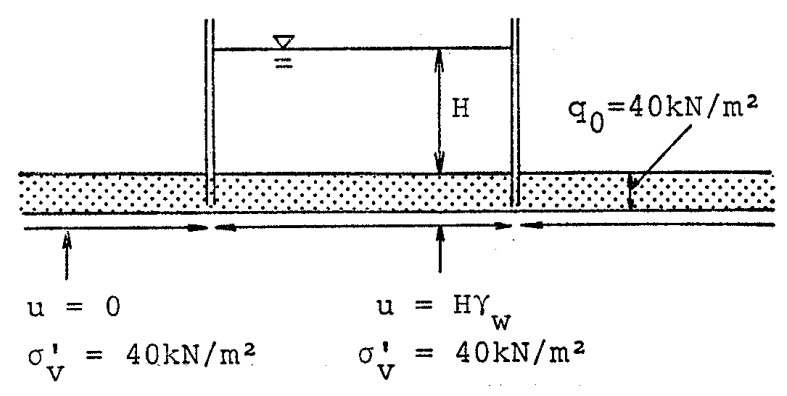

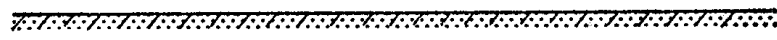
$\mathrm{u}=0$

Fig. 20. Seepage force application of loading rates is summarized in Figs. 21-22. Note that the range of loading rate examined in these figures is much broader than that of Figs. 18-19. The comparison between Figs. 19 and 22 yields the following findings:

(1) Partial drain effect on the increase of bearing capacity is incomparably expected in the case of loading through "porous membrane" more than that observed in the loading by a hydraulic potential boundary. This might suggest remarkable efficiency of placing "permeable sand mat" just below embanking area, the necessity of which has been commonly emphasized in the engineering practice of soft clay foundation.

(2) Again the undrained analysis that was given in Figs. 5-6 evaluates ultimate load intensity well under rapid loading condition also in this particular method of load

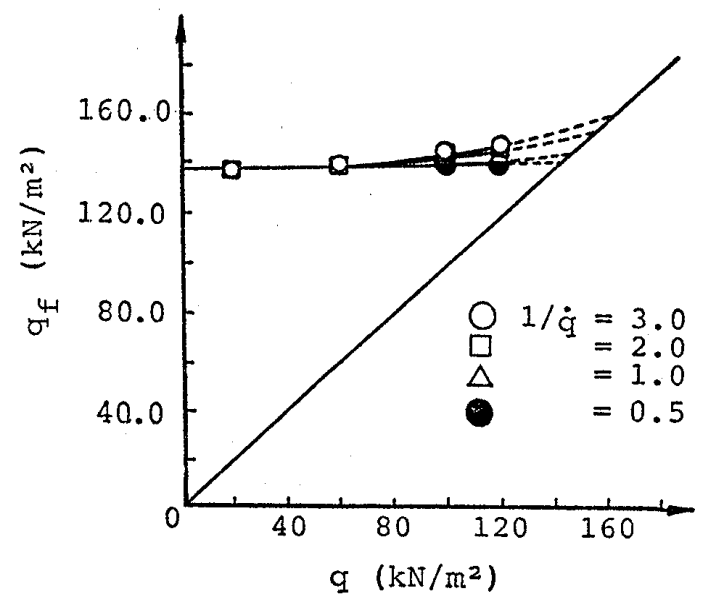

Fig. 21. Computation of partial drain effect by seepage force

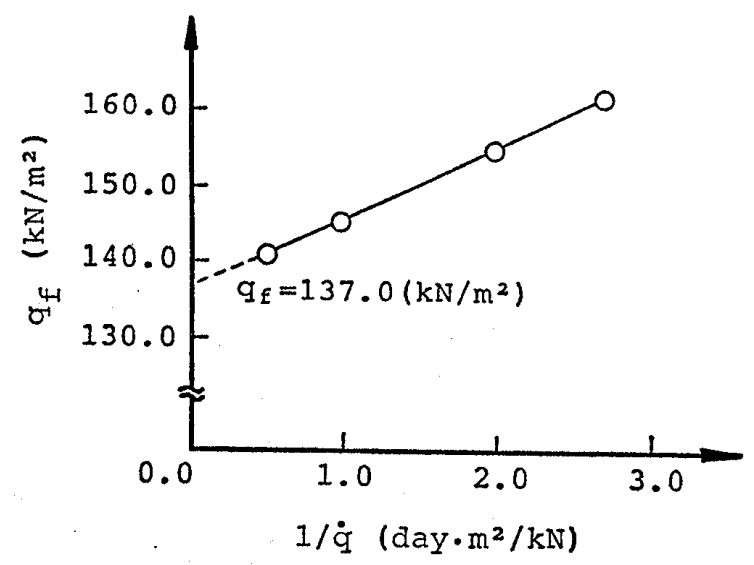

Fig. 22. Extrapolation of ultimate load (seepage force application) 
application. This can be seen clealy in Fig. 22 , in which the extrapolation of bearing capacity values is made towards $1 / \dot{q} \rightarrow 0$ condition.

Loading problem by a hydraulic potential boundary suggests another type of bearing capacity problem as discussed next.

\section{FULLY DRAINED ANALYSIS}

Coupling Equation and Numerical Procedure

Discussed here is another type of coupling problem, in which pore pressure distribution at limit state is given a priori. In this ploblem, therefore, the soil-water coupling equation becomes trivial:

$$
\left(p^{\prime}\right)_{f}=(p)_{f}-u_{a}
$$

in which $u_{a}$ denotes the pore pressure mentioned above and $(p)_{f}$ is the mean total stress that should be given by a solution of $\lambda$ in limiting equilibrium equations. Then, Eq. (31) is to be solved simultaneously with Eqs. (1)-(3), and with constitutive equations at critical state, Eq. (11) or Eq. (17). In this numerical procedure, the iterative method in which mean effective stress is given first arbitrary and its modification by the use of Eq. (31) is made employing limit state solutions in the former computation step will be useful.

The problem of this type is called a fully drained problem. This is so because, in this problem definition, flow of water in soil can be determined free from a failure mechanism of the soil. To the contrary, the failure mechanism itself is absolutely dependent of the flow of water. This is then still a coupling problem.

When constitutive relations given in Eqs. (11) and (17) are considered, it should be noted that if an initial stress ratio $\eta_{i j o}$ is known the fully drained analysis only requires, except for the unit weight of a soil, a single soil parameter, i.e., a critical state parameter $M$. Furthermore, as far as the constitutive relations at critical state is represented by Eq. (11) or (17), it is also noted that the limit state reached under fully drained condition has no effect of loading history.

\section{Illustrative Examples and Discussion}

As shown in Fig. 23, a typical stability problem solved under fully drained condition is observed in foundation failure of loose sand due to seepage forces below and along impermeable vertical wall. When high permeability is assumed, hydraulic potential and pore pressure distribution cen be determined by the usual steady state seepage analysis under given hydraulic boundaries. Referring to Fig. 23, a plane strain failure mode is considered, in which the problem concerned in this example should be the search of critical hydraulic potential $H_{c}$ on the top surface of loose sand deposit on the left hand side of the impermeable wall: An iterative method of this search is given in Fig. 24. In the analysis procedure, the impermeable wall is assumed smooth and rigid. The other necessary boundary conditions are given in Fig. 23.

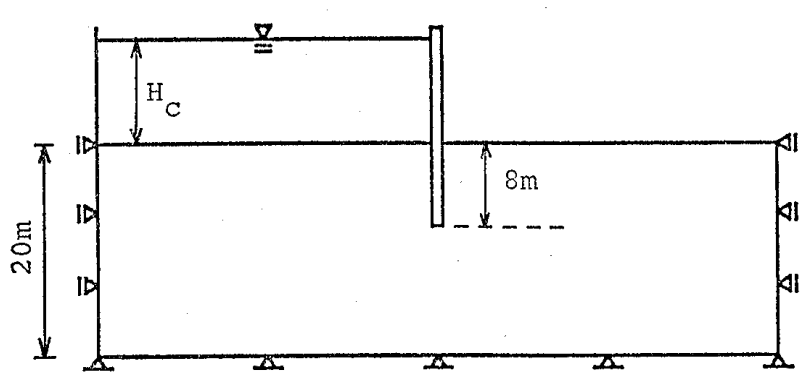

Fig. 23. Boundary condition employed for computation of critical hydraulic potential

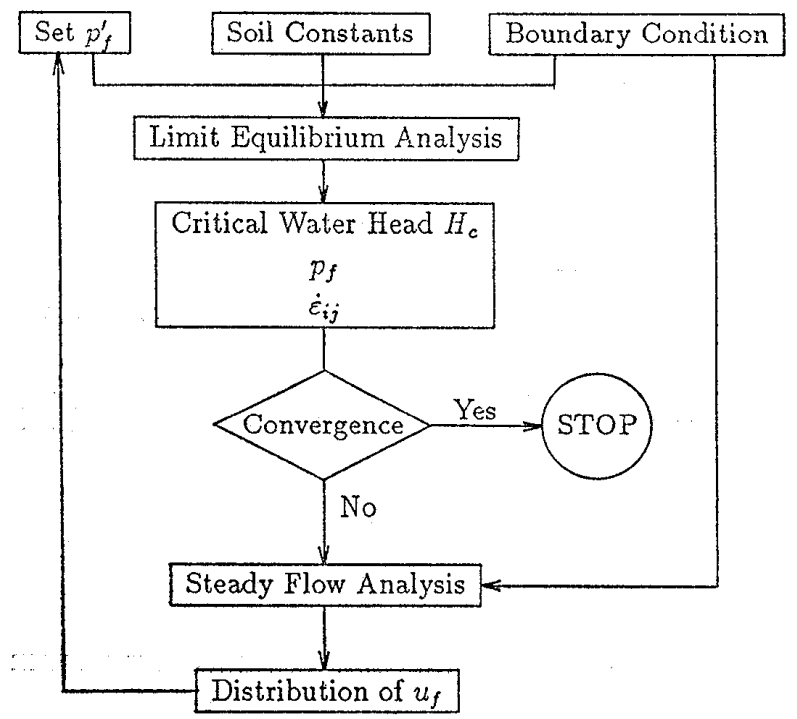

Fig. 24. Flow chart of analysis procedure 
The critical water head on the left of the wall is dependent of the critical state parameter $M$, as mentioned above. The problem of Fig. 23 was solved for a variety of critical state parameters assuming that the loose sand follows Eq. (11) at critical state and its initilal stress ratio is zero (Cam clay), for simplicity. The unit weight parameters used in the analysis are as follows:

$$
\begin{aligned}
& e=0.89, G_{s}=2.65, \gamma_{t}=18.36 \mathrm{kN} / \mathrm{m}^{3}, \\
& \gamma_{w}=9.8 \mathrm{kN} / \mathrm{m}^{3} .
\end{aligned}
$$

Fig. 25 summarizes computation results of the critical height of water $H_{c}$ on the left of the wall, in which the estimate of $H_{c}$ on the basis

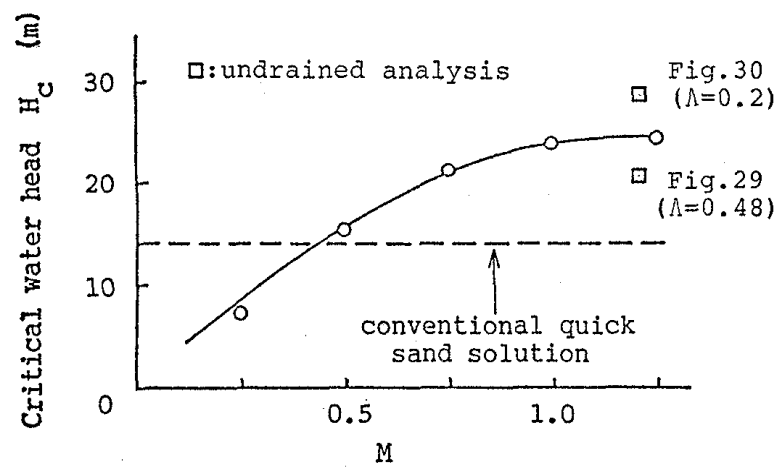

Fig. 25. Critical hydraulic potential versus critical state parameter

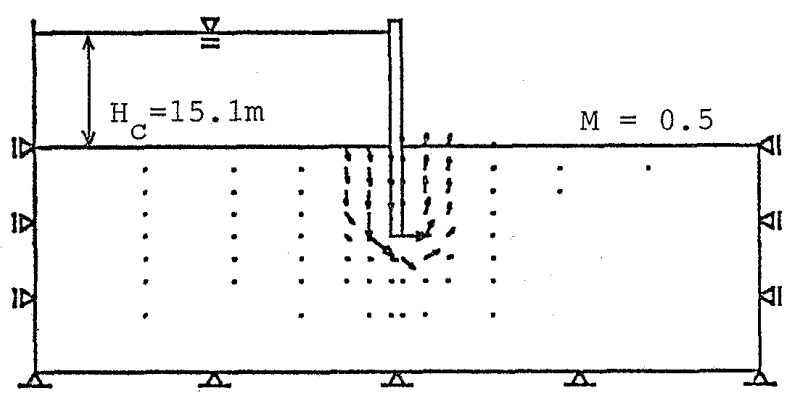

Fig. 26. Typical plastic flow at limit state due to seepage force

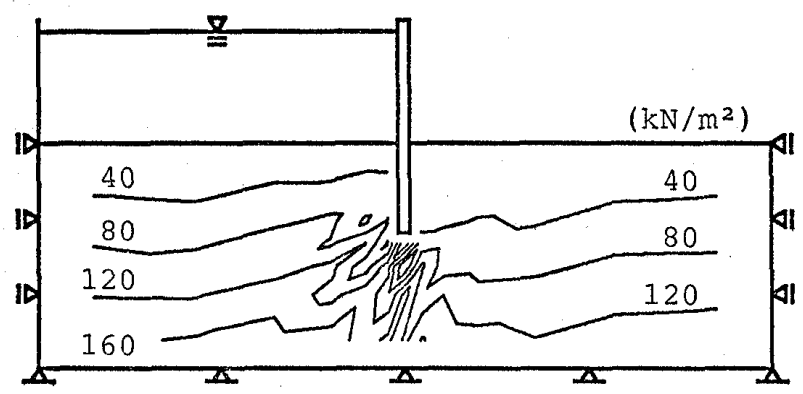

Fig. 27. Mean effective stress distribution at limit state of the conventional quick sand condition is also given. The conventional analysis that evaluates "one dimensional (vertical) limiting equilibrium condition due to upward seepage force" does not give the dependency of $H_{c}$ on the frictional angle of the sand.

A typical velocity field of the sand deposit at failure is given in Fig. 26, while Fig. 27 shows a mean effective stress distribution at limit state. These figures are corresponding to $M=0.5$. The shape of the plastic flow at limit state is also highly dependent of the critical state parameter. Fig. 28 is corresponding to $M=1.2$, which shows that when

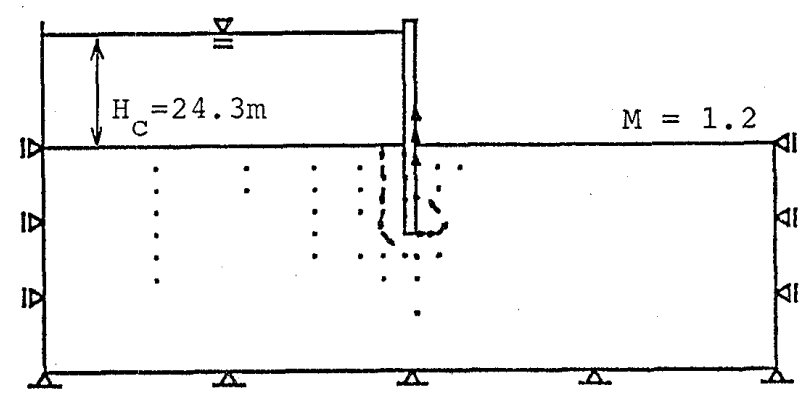

Fig. 28. The effect of critical stress parameter for plastic flow at limit state

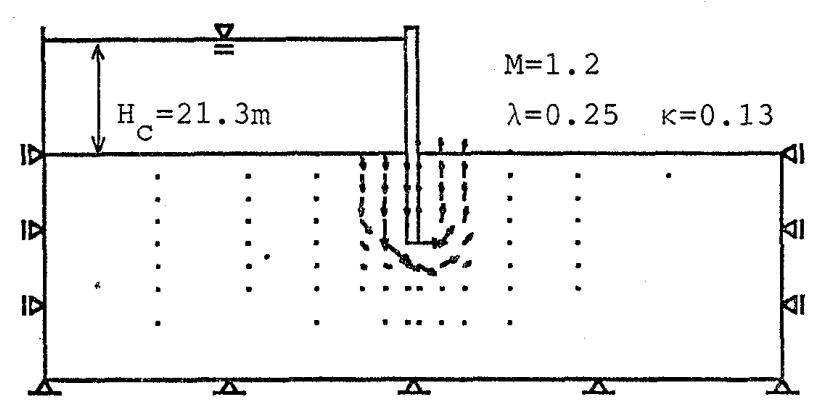

Fig. 29. Plastic flow of undrained loading $(\lambda=0.25, \quad \kappa=0.1304, M=1.2)$

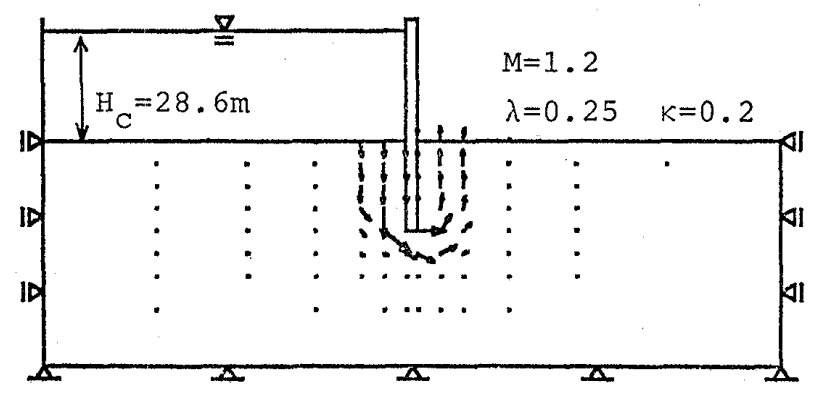

Fig. 30. Plastic flow of undrained loading $(\lambda=0.25, \kappa=0.2, M=1.2)$ 
$M$ is large significant velocity of soil skeleton is found only in a small region sticking to a wall.

The comparison between fully drained analysis and undrained anlysis is also given in Fig. 25. The problem of Fig. 23 is of course possible to be solved under undrained condition as examined before. Two sets of soil parameters are tried to give the example that drained analysis does not necessarily give higher ultimate load than that of undrained condition. Their corresponding velocity fields are shown in Figs. 29 and 30.

\section{CONCLUSION}

On the basis of analyses and discussions in the present study, following conclusions are drawn:

(1) Statically indeterminate limiting equilibrium analysis that has been developed for incompressible Mises-like material can be applied for saturated soils with the use of a soil-water coupling equations, if the soil exhibits only hardening behaviour during loading and when the hardening behaviour can be described with plastic volumetric strain. Therefore the analysis method discussed in the present study is applicable for the failure problem of Cam clay-like normally consolidated and lightly overconsolidated saturated soils.

(2) Two types of soil-water coupling problems were introduced: one is undrained problem and the other, fully drained problem. In undrained problems, all soil elements are assumed under undrained condition during whole loading stage before reaching limit state. The soil-water coupling equation links current effective stress state before undrained loading to the mean effective stress state at limit state. This was commonly found both for original Cam clay and the clay idealized by Sekiguchi and Ohta (1977).

(3) The undrained analysis also evaluates approximately the ultimate load that is applied through partly drained and/or partly swelling condition during the loading. For this purpose, the current effective stress state is necessary to be offered from time to time with gradual load application.

(4) In fully drained problems, the pore pressure distribution at limit state should be given a priori. A typical fully drained problem is found in foundation failure of loose sand due to seepage forces below impermeable vertical wall. The solution was found to evaluate the effect of internal friction angle of sand on the boundary value of critical hydraulic potential for the seepage failure.

\section{REFERENCES}

1) Asaoka, A. and Ohtsuka, S. (1986): "The analysis of failure of a normally consolidated clay foundation under embankment loading," Soils and Foundations, Vol. 26, No. 2, pp. 4759.

2) Asaoka, A. and Ohtsuka, S. (1987): "Bearing capacity analysis of a normally consolidated clay foundation," Soils and Foundations, Vol. 27, No. 3, pp. 58-70.

3) Carter, J. H. (1982): "Predictions of the nonhomogeneous behaviour of clay in the triaxial test," Géotechnique, Vol. 32, No. 1, pp. 55-58.

4) Cyras, A. A. (1983): Mathematical Models for the Analysis and Optimization of Elastoplastic Structure, Ellis Hollywood.

5) Maier, G. (1969): "Shakedown theory in perfect elastoplasticity with associated and nonassociated flow-laws: a finite element, linear programming approach," Meccanica, Vol. 4, No. 3, pp. 1-11.

6) Ohta, H. and Sekiguchi, H. (1979): "Constitutive equations considering anisotropy and stress reorientation in clay," Proc. of $3 \mathrm{rd}$ ICONMG, Vol. 1, Aachen, pp. 475-484.

7) Ohta, H., Nishihara, A. and Morita, Y. (1985): "Undrained stability of $K_{0}$-consolidated clays," Proc, of 11 th ICSMFE, San Francisco, Vol. 1, pp. 613-616.

8) Rochelle, P.L. and Marsal, R.J. (1981): "Slope stability, General Report (Session 11)." Proc. of 10 th ICSMFE, Stockholm, Vol. 4, pp. 485508.

9) Schofield, A.N. and Wroth, C.P. (1968): Critical State Soil Mechanics, London, McGraw-Hill.

10) Sekiguchi, H. and Ohta, H. (1977): "Induced anisotropy and time dependency in clays," Proc. of Specialty Session 9, 9 th ICSMFE, Tokyo, pp. 229-238.

11) Sekiguchi, H., Nishida, Y. and Kanai, F. (1981): "Analysis of partially-drained triaxial testing of clay," Soils and Foundations, Vol. 21, No. 
3, pp. 53-66.

12) Shibata, T. (1963): "On the volume change of normally consolidated clays," Disaster Prevention Research Institute Annuals, Kyoto University, No. 6.

13) Shibata, T. and Sekiguchi, H. (1980): “A method of predicting failure of embankment foundation based on elasto-viscoplastic a nalyses," Proc. of JSCE, 301, pp. 93-104 (in Japanease).
14) Shibata, T. and Sekiguchi, H. (1981): "Prediction of embankment failure on soft ground," Proc. of ICSMFE, Stockholm, Vol. 1, pp. 247250.

15) Tamura, T., Kobayashi, S. and Sumi, T. (1984): "Limit analysis of soil structure by rigid plastic finite element method," Soils and Foundations, Vol. 24, No. 1, pp. 34-42. 